\title{
Tracheal surgery
}

\author{
A. D’Andrilli, E.A. Rendina, F. Venuta
}

\section{ABSTRACT: Tracheal surgery. A. D'Andrilli, E.A. Rendina, F. Venuta.}

Surgical resection and reconstruction of the trachea can be performed both for benign and malignant diseases. The main indications for surgery include inflammatory (generally post-intubation), congenital or post-traumatic stenoses, degenerative lesions, benign or malignant neoplasms. Success can be pursued only by accurate patient selection and timing, meticulous surgical techniques, care- ful follow up and, when required, multidisciplinary cooperation.

Although surgical resection has now become part of our surgical practice, other treatment modalities are approaching a new clinical application era, in particular tracheal transplantation and bioengineering. These new techniques will certainly offer, in the near future, improved chances to treat difficult cases.

Monaldi Arch Chest Dis 2010; 73: 3, 105-115.

Department of Thoracic Surgery, University of Rome "Sapienza", Italy.

Correspondence: Prof. Federico Venuta, Cattedra di Chirurgia Toracica, Policlinico Umberto I, Università di Roma “Sapienza”, 00161 Rome, Italy; e-mail: federico.venuta@uniroma1.it

\section{Introduction}

Surgical resection and reconstruction of the trachea can be performed for benign or malignant diseases (Table 1). The main indications for surgery include inflammatory (generally post-intubation), congenital or post-traumatic stenoses, degenerative lesions, benign or malignant neoplasms. The vast majority of tracheal resections are performed for post-intubation lesions.

After intubation or tracheostomy, stenosis may occur due to an ischemic damage, initially of the mucosa and then of the complete tracheal wall. After extubation this may produce an aberrant scarring process determining a stricture of the airway lumen up to complete obstruction. Trans-laryngeal intubation may produce damage at the glottic or at the sub-glottic level (which is the narrowest part of the airway) due to the rigidity of the tube or, more distally, due to the cuff tension. In prospective studies, the duration of intubation has been found to be directly related to the incidence of mucosal damage, but not with the incidence of the permanent stenosis [1].

In patients with tracheostomy, similarly, the stricture may occur either at the level of the stoma or at the level of the cuff. In studies on large series of patients a tracheal stenosis in this site, after a period of mechanical ventilation with a cuffed tracheostomic cannula, has been reported in $12.5 \%$ of cases [2, 3]. The use of high-volume low-pressure cuffs in recent decades has allowed the significant reduction in the incidences of tracheal stenoses consequent to cuff hypertension. For the above mentioned reasons significant developments in tracheal surgery have been reported following the introduction of mechanical ventilators which were involved in Sweden in the 1950s and whose use spead thoughout the rest of Europe and North America in the 1960s.
In some cases, patients with severe stenosis and life-threatening obstruction of the trachea may require emergency treatment. Intravenous or inhaled steroids are immediately administered to reduce inflammation and oedema. Rigid broncoscopy under deep sedation or general anaesthesia is the life - saving procedure of choice. This technique is generally effective in restoring a good respiratory space by mechanical dilation, laser ablation or stent placement. Endoscopic techniques should never be abused as they can create serious problems for the subsequent surgical reconstruction. If possible, emergency tracheostomy should be avoided as it could extend the inflammatory disease and complicate the subsequent therapeutic steps. For this reason, when tracheostomy is unavoidable, it is advisable that it is performed through the damaged segment of the trachea.

Sometimes stenosis may be due to inflammatory granulations developing at the margins of the tracheostoma or in the area of ulceration determined by the cuff. These granulations are generally easily managed by endoscopic procedures (laser ablation, mechanical removal, stenting). Endoscopic management has been proposed in recent years as a possible alternative to surgical resection for benign stenosis of the trachea. However, results in this setting usually show that only a thin weblike stenosis can be successfully treated, while the benefit for more extended lesions are only temporary $[4,5]$.

Segmental resection and reconstruction are currently the option of choice to treat the vast majority of benign and malignant stenoses. Contraindications to surgery include the permanent requirement of mechanical ventilation, an excessively long extent of the lesion preventing primary anastomosis, a neurological impairment that compromises the possibility of the patient having con- 


\section{Table 1. - Tracheal disorders}

\section{Malignant Tumours}

Adenoid cystic carcinoma

Squamous cell carcinoma

Nonsquamous carcinoma

Mucoepidermoid carcinoma

Sarcoma

Carcinoid

Lymphoma

Melanoma

Metastatic disease

Direct invasion by thyroid or esophageal cancer

\section{Benign tumours}

Capillary hemangioma

Chondroblastoma

Chondroma

Fibrous histiocytoma

Glomus tumor

Granular cell tumor

Hamartoma

Hemangiomatous malformation of the mediastinum

Plasma cell granuloma

Leiomyoma

Neurogenic tumours

Paraganglioma

Pleomorphic adenoma

Pyogenic granuloma

Multiple or solitary squamous papilloma

Vascular tumours of borderline malignancy

\section{Congenital \\ Stenosis \\ Atresia \\ Malacia}

\section{Post-traumatic}

Cervical trauma

Mediastinal trauma

\section{Postintubation stenosis}

After endotracheal intubation

After tracheostomy

Infectious/Inflammatory
Idiopathic
Tuberculosis
Histoplasmosis
Sarcoidosis
Amiloidosis
Wegener's granulomatosis

trol of his/her body (tetraplegia) or being able to tolerate neck flexion post-operatively.

\section{Subglottic resections}

The subglottic space at the cricoid level is the narrowest part of the airway. It extends from the inferior margin of the vocal cords to the lower border of the cricoid cartilage. Interventional bronchoscopic treatment modalities including laser and stenting, whose application in tracheal surgery has greatly increased in recent years, have a limited role in subglottic stenosis due to anatomic and technical reasons [6]. These techniques are therefore mainly employed to stabilise the stenosis before surgery or to achieve an acceptable palliation in patients who are not suitable for surgery. However, the benefit is usually temporary and repeated procedures are often necessary.

When considering surgical treatment, a stenotic disease involving the subglottic region present increased technical problems, principally due to the need to extend the resection to the cricoid cartilage, next to the vocal cords (fig. 1). Particular care must be taken when considering resection of the cricoid cartilage since the laryngeal nerves have access into the airway wall at the level of its posterior plate, where the upper border supports the arytenoid cartilages playing a major role in correct vocal cord function.

The initial experience of segmental resections of the cricoid cartilage was reported by Ogura and Powers in 1964 [7] and included a series of 7 patients undergoing primary thyro-tracheal anastomosis. However, no attempt to preserve the laryngeal nerves was required since they were irreversibly damaged on both sides as a result of the trauma.

In 1974 Gerwat and Brice [8] described an original technique to preserve the posterior cricoid plate and the recurrent nerves above the level of the crico-thyroid joints by using an oblique line of resection in order to remove only the anterior cricoid arch. The upper transection line begins at the inferior border of the thyroid cartilage anteriorly and passes below the crico-thyroid joints behind. However, this technique allowed a limited extent of resection of the posterior subglottic structures.

Pearson in 1975 [9] proposed a modification of this technique which allowed transverse resection of the subglottic airway at any level below the vocal cords, with preservation of a posterior shell of the cricoid cartilage sparing the laryngeal nerves. With this technique the line of division passes a

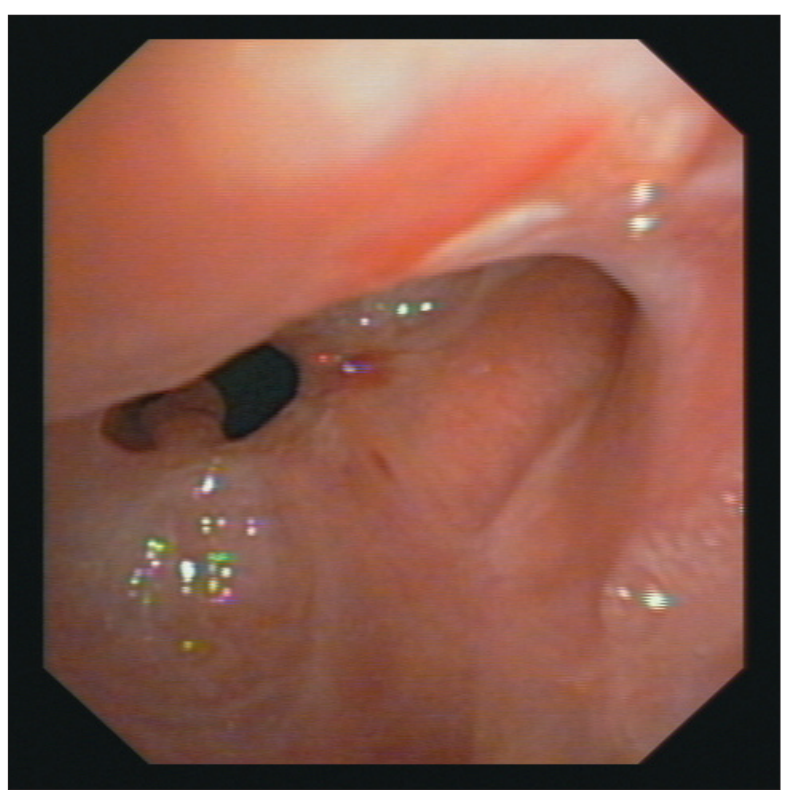

Fig. 1. - Postintubation subglottic tracheal stenosi: endoscopic view. 
few millimetres below the vocal cords. Thus, primary thyro-tracheal anastomosis can be performed at less than $1 \mathrm{~cm}$ from the vocal cords. This is still the most frequently used technique to date.

Before resecting the anterior portion of the cricoid arch, the trachea is sectioned below the stenotic segment, and the distal airway is intubated through the operative field by an armoured endotracheal tube. When isolating circumferentially the diseased segment of the upper trachea there is generally no need to identify the laryngeal nerves (which are frequently involved in the surrounding scar tissue), since maintaining dissection close to the surface of the trachea can be sufficient to avoid injuries to these structures. The antero-lateral aspect of the cricoid cartilage is then freed completely from their pericondrial cover and resected. A discrepancy in diameter between the lumen of the subglottic airway and the distal trachea at the time of reconstruction is inevitable. The end-toend primary thyro-tracheal anastomosis is usually performed using interrupted sutures of 3-0 or 4-0 absorbable material (usually PDS). Although Pearson and colleagues [9] suggested plicating the pars membranacea of the distal trachea to reduce this difference in terms of diameter, this procedure may be not necessary in many cases, since the elasticity of the distal trachea allows adequate compensation.

In some patients the post-intubation subglottic stenosis may be complicated by glottic injury at the level of the posterior interarytenoid space. In such cases, when the interarytenoid scar is excised, a posterior mucosal defect is created. This defect can be covered by a pedicled flap of pars membranacea fashioned from the distal trachea and created by resecting one or two cartilaginous rings on the anterior aspect.

When the thyro-tracheal anastomosis is performed very close to the vocal cords there is an unpredictable risk of post-operative glottic oedema. This complication can be managed by placing, at the end of operation, a small tracheostomy or a silicone Montgomery T-tube distal to the anstomosis. These can be left in for a variable period of time: weeks or even months, depending on the status of the glottis and of the anastomosis.

In cases of tight stenosis, some problems may arise at the time of intubation, before the resection; the stenosis can be dilated by a gum-tipped bougie or by a rigid bronchoscope. In our experience [10], a small calibre (4-4.5) endotracheal tube is passed through the stenosis, and this is usually sufficient for adequate ventilation until the trachea is exposed and incised allowing cross-field intubation. Occasionally the tube can be placed immediately above the stenosis.

Some other reconstruction techniques have been proposed in recent years to manage laryngotracheal stenosis with the aim of obtaining a permanent enlargement of the subglottic airway. These procedures, principally popularised by otorinolaryngologists, include the vertical division of the anterior and posterior wall of the cricoid cartilage and the insertion of an autologous tissue graft between the divided cartilaginous portions. This is particularly frequent in the pediatric population. Free pieces of bone or cartilage have been used as grafts. McCaffey [11] has reported a series of 21 patients with subglottic stenosis treated with the interposition of a costal cartilage graft in the anterior vertical incision of the cricoid and the thyroid cartilage. Although the incidence of satisfactory results was high $(76 \%)$, there was a $24 \%$ rate of patients that could not be extubated.

The major series of laryngo-tracheal resection published in the international literature report a high rate of good or excellent results, with low mortality (generally under 1-2\%), supporting the role of surgery as the treatment of choice [10, 12-17].

Pearson and colleagues $[9,12]$ reported the results of a series including 38 patients treated using their technique of partial cricoid resection and primary thyro-tracheal anastomosis. Recurrence of stenosis occurred in 2 patients and was successfully managed by re-resection in 1 case and by dilation and laser ablation in the other. There was no mortality. Ultimately, therefore, good results were achieved in all patients. This series included also 16 patients presenting with combined laryngeal and subglottic lesions. These complex stenoses were managed by synchronous subglottic resection and laryngeal reconstruction. Decannulation and subsequent stable satisfactory results were achieved in all the patients but one.

Grillo and coworkers [13] reported the outcome of 80 patients undergoing subglottic resection and reconstruction with the use of their modified technique. Fifty of these patients had a postintubation injury. There was 1 operative death. All 49 survivors of this group presented satisfactory to excellent results.

One of the largest published experiences of laryngo-tracheal resection has been reported by Couraud and colleagues [14], which included 57 patients with post-intubation stenosis involving the subglottic region alone or in combination with the larynx out of a total of 217 patients with benign tracheal stenosis. Results were excellent or good in $98 \%$ of the cases. There was one perioperative death (1.8\% overall mortality).

We have recently published our experience of laryngo-tracheal resection for benign stenosis over a 16-year period reporting long-term results (mean follow-up 61 months) [10]. In a series of 35 consecutive patients, immediate excellent or good anatomic and functional results were observed in $85.7 \%$ of the cases. Four patients $(11.4 \%)$ presented with recurrence of stenosis that was successfully treated by endoscopic procedures. One patient $(2.9 \%)$ presented with anastomotic dehiscence that required a temporary tracheostomy closed after one year with no sequelae. Long-term results were good or excellent in $94.3 \%$ and satisfactory in $5.7 \%$ of the patients. This series included 9 patients with neurological or psychiatric post-coma disorders. The outcome was good or excellent also in this group, suggesting that such a condition should not be considered an absolute contraindication for surgery any more. 
The results of the larger experiences of laryngo-tracheal resection published since 1995 are reported in table 2 .

\section{Tracheal resections}

The main indications for tracheal resection and reconstruction include post-intubation stenosis, idiopathic stenosis, and primary tracheal tumours. Less frequently reconstructive procedures are performed to repair tracheo-esophageal fistulas. As for the subglottic district, postintubation injuries are the most frequent lesions amenable for tracheal resection.

Primary tracheal tumours are rare. It has been estimated that they occur with an incidence of 2.7 new cases per one million population per year in North America [18]. Squamous cell carcinoma and adenoid cystic carcinoma account for two thirds of primary tracheal tumours.

Surgery is the treatment of choice for benign and malignant neoplasms. Radiotherapy in this setting is indicated as an adjuvant after resection, for unresectable or medically inoperable tumours, and for palliation of severe symptoms [19].

In case of tumours determining life-threatening obstruction, rigid broncoscopy and endoluminal resection can be used to stabilise the respiratory status before attempting complete resection. Management with stent or neoadjuvant radiotherapy is not recommended unless complete resection is not feasible.

The maximal length of diseased trachea that can be resected has always been a crucial issue. In the initial era of tracheal surgery the interest was principally focused on the experimental use of prosthetic materials in order to test the feasibility of long tracheal segment resections [20-24]. A number of options were employed including Dacron, Polytetrafluorethylene, glass and stainless steel meshes. Despite some experimental encouraging results, the clinical application of prosthetic materials proved unsuccessful, with occlusion, infection, vascular erosion or anastomotic dehiscence occurring in almost all cases.

Concurrently, there was the evolution of the primary reconstruction techniques. The earliest re- ports of tracheal resection and reconstruction described only limited resections not exceeding $2 \mathrm{~cm}$ of trachea.

Grillo $[25,26]$ performed cadaveric studies to assess the possibility to safely resect longer airway segments. He found that with a standard tension of $1000-1200 \mathrm{~g}$, it was possible to resect a median length of up to $4.5 \mathrm{~cm}$ of the trachea without producing excessive anastomotic tension and compromising the blood supply. In these studies the author highlighted that the tracheal dissection has to be conducted only anteriorly and posteriorly to preserve the lateral vascular pedicles that represent the main vascular supply to the trachea, originating as anastomotic branches from the inferior thyroid artery above and the bronchial arteries below.

Increasing technical experience in this field has proved that it is possible to resect with end - to - end anastomosis up to $50 \%$ of the length of the trachea in the adult. Patient's young age, elasticity of the tracheal wall, and the absence of previous treatment may positively influence the potential extent of the resection.

Before surgery, a clear diagnosis and accurate pre-operative assessment of the extent and characteristics of the airway lesion is mandatory. These are achieved by radiologic and bronchoscopic procedures. High resolution CT scans with three dimensional reconstruction offer some advantages with respect to standard radiological techniques since it perfectly illustrates the longitudinal extension of the stenosis and effectively defines the extraluminal component of the lesion, which is a crucial for malignant disorders. Flexible broncoscopy performed while the patient is awake is mandatory as it allows direct evaluation of the motility of the vocal cords as well as biopsy for malignant disorders. Moreover, this is the most effective means to assess the endoluminal extent of the lesion and the status of the trachea next to the stenotic segment. In the case of inflammatory disorders, the presence of active inflammation of the mucosa on the border of the stenosis is still considered a major contraindication for surgery and requires stabilisation towards scarring to avoid anastomotic complications and recurrence of stenosis.

Table 2. - Results of laryngo-tracheal resections for benign stenosis

\begin{tabular}{lcccccccc}
\hline \multirow{2}{*}{ Author (yr) } & Pts & \multicolumn{2}{c}{ Results } & Re-sten. & Compl. & Mortality & Re-op & Dehiscen \\
\cline { 2 - 7 } & & Successes & Failures & & & & & \\
\hline Grillo15 ('95) & 62 & $9 \%$ & $8 \%$ & $5.5 \% *$ & $33 \%$ & $2.4 \%$ & $3.4 \%$ & $5.5 \% *$ \\
\hline Couraud14 ('95) & 57 & $98.2 \%$ & $1.8 \%$ & $0 \%$ & $3.5 \%$ & $1.8 \%$ & $0 \%$ & $1.8 \%$ \\
\hline Macchiarini16 ('01) & 45 & $96 \%$ & $4 \%$ & $4.4 \%$ & $41 \%$ & $2 \%$ & $2.2 \%$ & $0 \%$ \\
\hline Ashiku17 ('04) & 73 & $91 \%$ & $9 \%$ & $8.3 \%$ & $8.2 \%$ & $0 \%$ & $0 \%$ & $0 \%$ \\
\hline D'Andrilli10 ('08) & 35 & $\begin{array}{c}\text { Early 85.7\% } \\
\text { Definitive 100\% }\end{array}$ & $\begin{array}{c}\text { Early 14.3\% } \\
\text { Definitive 0\% }\end{array}$ & $11.4 \%$ & $11.3 \%$ & $0 \%$ & $0 \%$ & $2.9 \%$ \\
\hline * recurrence of stenoses + dehiscences. & & & & & &
\end{tabular}


As reported for subglottic resections, a mechanical dilation of the stenosis may be indicated pre-operatively to allow the anaesthesiologist to introduce the endotracheal tube below the obstructive lesion. In case of tumours, laser ablation may be required to restore a sufficiently patent airway lumen before the operation.

Resection of the cervical trachea can be managed generally through a collar neck incision without requiring partial or total sternotomy. For lesions involving the mediastinal trachea, exposure can be improved by an upper partial sternotomy, obtaining a T-shaped incision. Since the carina lies at the level of the Louis angle, this approach may be sufficient, avoiding the need for a complete median sternotomy, or carinal resection and reconstruction. However, resection of the distal trachea, with or without carinal involvement, is usually approached through the right thoracotomy.

Intraoperatively, flexible bronchoscopy may help to precisely localise the lesion. As reported for subglottic stenosis, dissection close to the tracheal wall helps to avoid injury to the recurrent nerves which lie in the tracheo-esophageal groove on both sides. Care must be taken to avoid perforation of the oesophagus when dissecting circumferentially the trachea.

After isolation of the diseased trachea (fig. 2) and transection of the trachea distally to the lesion, the distal trachea is intubated through the operative field (fig. 3) as previously reported in case of subglottic resections. Some authors [27] prefer to retract the oro-tracheal tube proximally to the airway division and to pass a high frequency catheter through the endotracheal tube in the distal part of the trachea to continue ventilation.

After the resection of the diseased tracheal segment (fig. 4), circumferential dissection of the residual proximal and distal airway is limited to less than $1 \mathrm{~cm}$ to protect the segmental blood supply that enters laterally. Devascularisation of the remaining trachea to be anastomosed may induce ischemic problems with potential anastomotic dehiscence.

When resection of a long tracheal segment is required, in order to avoid excessive tension on the anastomosis, adjunctive release manoeuvres may add significant technical advantages. The most effective technique to release tension on the upper and middle trachea is the suprahyoid release described by Montgomery [28]. It consists of a small horizontal incision dividing the muscles inserting on the superior aspect of the hyoid bone. This manoeuvre is able to provide 1 to $2 \mathrm{~cm}$ of additional length of trachea. Another laryngeal release, the crycothyroid release described by Dedo and Fishman [29] is more rarely used because it may cause significant risks to swallowing. Another effective release technique used to mobilise the distal trachea is the hilar pericardial release that is usually performed in cases of resection which require right thoracotomy.

The reconstruction is usually performed with the use of interrupted sutures of 3-0 or 4-0 absorbable material (fig. 5) as previously indicated.

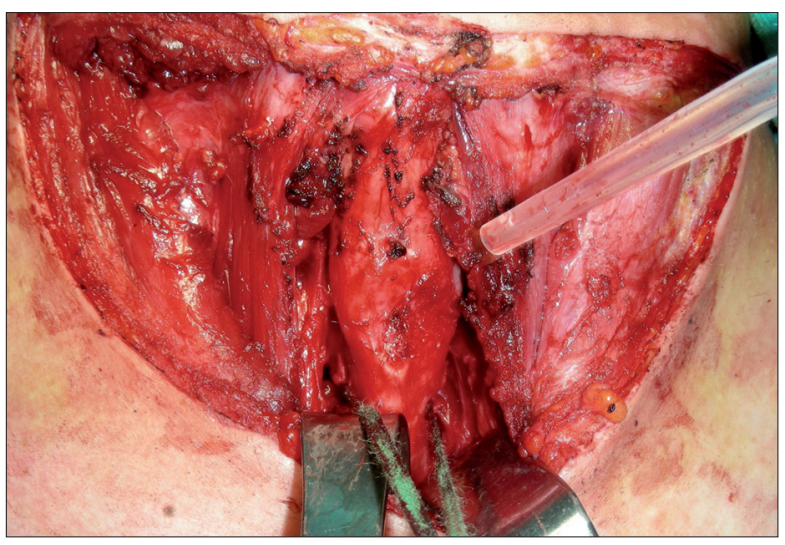

Fig. 2. - The stenotic segment is isolated and encircled.

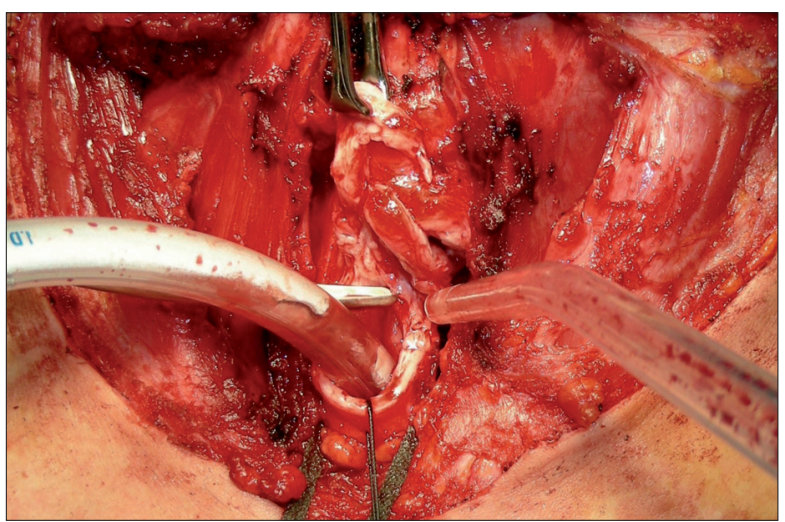

Fig. 3. - After transection the distal airway is intubated through the operatory field.

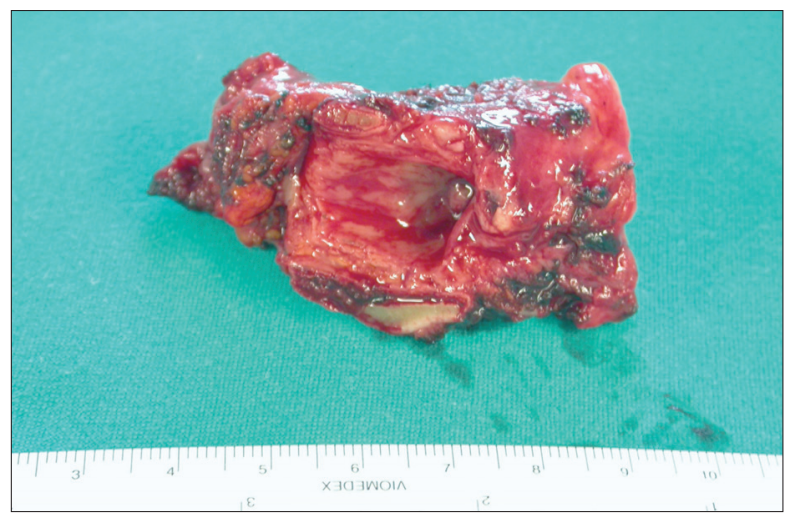

Fig. 4. - The stenotic trachea is resected.

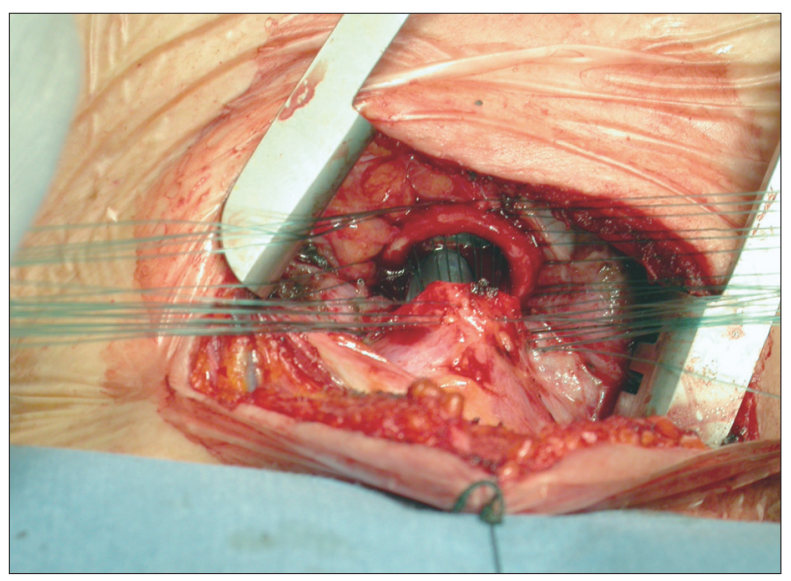

Fig. 5. - Stiches are placed circumferentially. 
Once all the anastomotic sutures have been placed, the cross - field endotracheal tube is removed, the oro-tracheal tube is re-advanced over the anastomosis and the stitches are tied (fig. 6). Some surgeons prefer to extubate the patient in the operative room at the end of the tracheal reconstruction. We, as other authors $[10,14]$ commonly leave a naso-tracheal tube uncuffed in site, with the distal end beyond the anastomosis for 24 hours postoperatively. This tube allows adequate toilette of the airway soon after the operation protecting the anastomosis. Some other authors [30] leave a small endotracheal tube in place for 48 hours postoperatively only when a laryngeal oedema is present at the moment of extubation. Also protective tracheostomy has been advocated.

Couraud in 1995 [14], in a series of 217 operations for non-tumoural laryngo-tracheal or tracheal stenosis, reported 120 resections for lesions not involving the larynx. Seventy-six percent of these resections that were at the level of the cervical trachea and of the cervico-thoracic junction were approached by a neck incision. The cervical approach was combined with sternotomy in $23 \%$ of the patients. Only in one case was the resection performed through a right thoracotomy. The results were excellent or good in $97 \%$ of the cases in terms of re-establishment of respiratory function and airway patency. Phonation was equally restored with good to fair results. There were 3 postoperative deaths: one was due to complete anastomotic dehiscence and fatal haemorrhage, one as a result of cerebrovascular accident and one to respiratory failure.

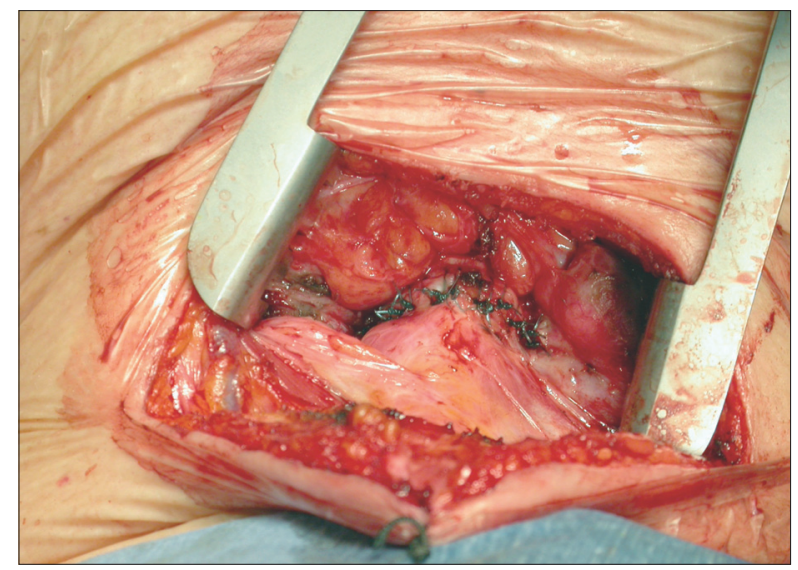

Fig. 6. - The stitches are tied.

The group from the Massachusetts General Hospital, which has obtained probably the greatest experience in the world, has recently reported its findings from 1975 to 2003 including 901 resections of the trachea, 281 of which were laryngotracheal resections. Surgery was performed for postintubation stenosis in most cases (589). Other indications for resection were tumours (208 patients), idiopathic laryngo-tracheal stenosis (83) and tracheo-esophageal fistula (21) [31]. The overall success rate was $95 \% .4 \%$ of the patients had a permanent tracheostomy or T-tube. Overall periop- erative mortality was $1.2 \%$. The group of patients with idiopathic laryngo-tracheal stenosis obtained the best results $(98.8 \%)$. This finding may be partially justified by the relatively short segment resected in these patients. The success rate in patients with tumour and post-intubation injury was $97.1 \%$ and $95.2 \%$, respectively. The worst results were observed, as expected, in the group of patients undergoing resection for tracheo-esophageal fistula $(90 \%)$.

Complications occurred in $18.2 \%$ of the patients with a higher incidence in those with tracheo-oesophageal fistula. Anastomotic complications occurred in $9 \%$ of the cases, ranging between $14.3 \%$ in the group with tracheo-esophageal fistula and $2.4 \%$ in those with idiopathic tracheal stenosis. Significant risk factors for anastomotic complications were: the need to reoperate, diabetes, length of resection longer than $4 \mathrm{~cm}$, laryngeal involvement and previous tracheostomy.

In the series of 503 patients reported by Grillo [15] the most frequent complications included anastomotic dehiscence and recurrence of stenosis, laryngeal dysfunction and infection. Major complications such as haemorrage from innominate artery and tracheo-esophageal fistula occurred in less than $1 \%$ of patients. Most perioperative deaths were related to anastomotic dehiscence.

When considering tracheal resection for tumour, epidemiological studies [32-34] show that in most patients the malignant disease is locally advanced at the time of diagnosis and therefore it is treated with non-surgical modalities. The possibility of undergoing complete resection significantly improves the prognosis of these patients

A national survey in the UK in the early 1990s reported a 5-year survival rate for squamous cell carcinoma (which is the most frequent type) of $39 \%$ for patients undergoing surgery compared to $7 \%$ for patients undergoing medical treatment (chemo-radiotherapy [35]).

Similarly, a more recent national study conducted in Denmark has reported a 52\% 5-year survival rate in patients undergoing resection for adenoid cystic tumours compared to $33 \%$ in non surgically treated patients [33].

Operations performed to treat tracheal tumours include resection of the trachea at any level, of the laryngo-tracheal district, of the carina and of the carina and lungs. Contraindications to surgery include the presence of extensive lymph node involvement, longitudinal infiltration of more than $50 \%$ of the trachea, mediastinal invasion of surrounding (unresectable) organs, previous mediastinal high-dose radiotherapy and distant metastases [36, 37].

Long-term results of worldwide major experiences of surgery for tracheal tumours are reported in table 3 suggesting a more favourable prognosis for resectable tumours [36, 38-40].

In the largest published series $[36,41]$ the presence of negative tracheal margins, complete resection and the adenoid cystic histology showed a favourable impact on long-term survival. Tumour depth and length, and nodal status were not predictive of survival, but the lack of significance 
Table 3. - Survival after resection for malignant primary tracheal tumours

\begin{tabular}{lccccc}
\hline Author(yr) & pts & Histology & Follow-up (years) & 5-yr survival & 10-yr survival \\
\hline Regnard38 (1996) & 94 & Squamous cell carcinoma & 23 & $47 \%$ & $36 \%$ \\
& 65 & Adenoid cystic tumours & 21 & $73 \%$ & $51 \%$ \\
\hline Perelmann39 (1996) & 66 & Squamous cell carcinoma & 29 & $36 \%$ & $27 \%$ \\
& 21 & Adenoid cystic tumours & & $79 \%$ & $51 \%$ \\
\hline Mazrak40 (1996) $^{2} 32$ & Adenoid cystic tumours & 32 & $39 \%$ & $18 \%$ \\
\hline Gaissert36 (2004) & 90 & Squamous cell carcinoma & & $52 \%$ & $29 \%$ \\
\hline
\end{tabular}

could be due to the limited numbers and the not systematically reported lymphadenectomy. Conversely, some authors $[33,34]$ have shown a significant correlation between staging and survival in patients undergoing surgery.

\section{Tracheal transplantation}

Tracheal resection with primary reconstruction, which is currently the only curative treatment for most benign or malignant diseases, can be performed for a maximal length of $50 \%$ of the trachea in adults. Resection of longer segments would require the interposition of a fully biocompatible functional tracheal replacement. Attempts to provide autologous or synthetic grafts for human application have been carried out over recent decades with disappointing results $[42,43]$.

Tissue bioengineering has provided functional human organ replacement in other surgical settings, and this has recently stimulated active research both in vitro and in the animal model for a potential application in airway reconstruction. Encouraging results have been obtained in mouse and pig models with the development of a streamlined process in which autologous epithelial and mesenchimal stem-cell-derived condrocytes are seeded onto a decellularized donor tracheal scaffold and matured in a novel bioreactor system [44, 45]. The absence of an immunological response to this tracheal graft observed in the animal model has promoted the implantation of a tissue engineered tracheal construct in the human for airway reconstruction $[44,45]$.

Macchiarini in 2008 has reported the first case of implantation in a patient with end-stage airway disease of a decellularised human donor trachea, colonised by the recipient's epithelial cells and condrogenic mesenchymal stem cells [45]. The recipient was a 30-years old woman with severe bronchomalacia and the graft was used to replace the stenotic left main bronchus. No major complications were reported and immediate improvement of quality of life was observed after the intervention. Microvascular recording performed by a laser Doppler probe at 2 months documented a normal blood flow at the level of the graft. During the bronchoscopic check-up performed after 4 months, the graft presented normal appearance and mechanical properties. The patient had no donor antibodies and was not on immunosuppressive drugs. A temporary endoluminal stent was placed 8 months after the operation due to a proximal collapse of the graft [44].

This clinical experience has shown that a cellular, tissue engineered airway is free from risks of rejection and with mechanical properties allowing normal functioning can be produced. Further clinical application and long-term follow-up will indicate if this technique could be proposed in the future as a standardised therapy.

\section{Carinal resections}

Resection and reconstruction of the carina is indicated for tumours invading the origin of the main bronchus, the tracheo-bronchial angle, or the carina itself, but not extending extensively in the lower trachea and in the contralateral main bronchus; this would make the anastomotic reconstruction unfeasible due to excessive tension. Carinal resection can be performed without pulmonary resection, in association with right or left pneumonectomy (right or left carinal pneumonectomy), or in association with lobar resection (right upper lobe).

The safe maximal extent of resection between lower trachea and main bronchus is generally considered to be $4 \mathrm{~cm}$. This limit has to be particularly considered in cases of carinal right pneumonectomy which require the anastomosis of the distal trachea with the left main bronchus whose upward mobilisation is limited by the aortic arch.

Most carinal resections are performed for right side bronchogenic tumours since left side tumours rarely extend up to the carina without infiltrating the aorta and the subaortic space, thus being unresectable. Increasing experience in surgical and anaesthetic technique, and more accurate selection of patients, have contributed in recent years to improve short-term and long-term results. However, these interventions have still not reached wide acceptance due to the potentially high risk of complications; in fact, only a few centres worldwide 
have obtauined a good level of experience of these interventions.

Early experiences with carinal resection, with or without right pneumonectomy, have been reported at the end of 1940s describing reconstruction techniques either with the use of prosthetic materials or with a complex tracheo-bronchial anastomosis; however, at that time the incidence of technical complications was excessively high. Barclays in 1957 [46] described his technique of carinal reconstruction by end-to-end anastomosis of the right main bronchus to the distal trachea and concurrent end-to-side anastomosis of the left main bronchus to the bronchus intermedius using interrupted sutures.

In the subsequent years some other authors [47-49] reported small series of patients undergoing successful resection and reconstruction of the carina for bronchogenic carcinoma. Grillo and coworkers in 1963 [50] reported the first large series of patients undergoing carinal resection. In the same year Mathey and colleagues [51] analysed their results on a series of 20 patients concluding that circumferential carinal resection resulted in a better outcome when compared with non circumferential excision.

Anaesthetic technique: As for tracheal and laryngo-tracheal resections, close cooperation between the surgeon and the anaesthesiologist is crucial; in fact, one of the key factors during the operation is maintaining ventilation while having optimal exposure.

In the early days, a long oro-tarcheal tube passed through the divided trachea into the main bronchus to be reanastomosed was employed [47]. In 1963 Grillo [50] described for the first time the use of a sterile tube placed through the operative field in the distal airway (usually the contralateral main bronchus in case of carinal pneumonectomy) once the airway has been divided. This is still the most frequently used technique. Alternatively, a high frequency jet ventilation catheter (100-150 per minute) delivering a small tidal volume has been proposed since the early 1980s [52]. A similar method using a continuous oxygen delivery through a high flow catheter has been used [53], but this technique has the disadvantage of producing carbon dioxide retention.

Although some authors have emphasised the role of double lumen tubes [54], they are rarely employed due to rigidity and diameter limiting surgical exposure and the difficulty to adapt the tube to the distal airway.

Surgical approaches: As initially indicated by Pearson in 1984 [55] median sternotomy is generally considered the approach of choice for isolated carinal resection. Although this operation can be alternatively performed through a right thoracotomy, the sternotomic incision offers the advantage of allowing simultaneous laryngeal release manoeuvres or both right and left pulmonary hilar release if required intraoperatively, and it provides adequate exposure for any type of pulmonary resection, including left pneumonectomy.

Carinal resection associated with pulmonary resection is generally approached through an ipsi- lateral thoracotomy. However on the left side, exposure of the lower trachea and of the left main bronchus is limited by the aortic arch and the mobilisation of this structure is usually required. For this reason median sternotomy is the favoured approach also for left carinal pneumonectomy since it provides optimal exposure of the tracheobronchial bifurcation and causes less incisional discomfort. The main disadvantages include the need for cardiac retraction to expose the left hilum, and the increased difficulty to dissect pleural adhesions. Alternatively, a clamshell incision (anterior bilateral thoracotomy with transverse sternotomy) has been proposed, but it has the disadvantage of requiring opening of the contralateral pleura and has the potential risk of a sternal pseudoarthrosis.

Anastomotic technique: The end-to-end tracheo-bronchial anastomosis can be performed using interrupted sutures of 3-0 or 4-0 absorbable material. Some authors [56] have described alternative techniques with the use of 4-0 absorbable monofilament running suture on the deepest part of the airway and interrupted sutures of the same material in the remaining part of the anastomosis. If an end-to-side anastomosis has to be performed the lateral side of the trachea (cartilaginous part) is incised in an ovoid fashion and the bronchus anastomosed with one of the above described techniques. Careful dissection before anastomosis avoids devascularisation of the airway and precise placement of sutures is crucial to avoid size discrepancies.

To allow adequate mobilisation of the airway and avoid tension on the anastomosis, a pericardial hilar release at the level of the pulmonary veins can be added. Additionally, dissection of the pretracheal plane can be performed at the time of mediastinoscopy which is usually carried out before the operation for staging purposes ( $\mathrm{N} 2$ disease should be a contraindication to surgery). Laryngeal release is rarely required for carinal resections.

Carinal reconstruction without pulmonary resection is indicated only for tumours limited to the carina. For very small tumours not involving the origin of the main bronchi and the distal trachea the reconstruction can be performed by approximating the medial wall of the main bronchi in a "new carina" fashion, and anastomosing this "new carina" to the trachea. In the case of tumours infiltrating the distal trachea, end-to-end anastomosis plus an end-to-side anastomosis with various options should be preferred.

Barclays [46] described an end-to-end anastomosis between the trachea and the right main bronchus and an end-to-side anastomosis of the left main bronchus with the bronchus intermedius. This technique has a limitation in relation to the difficultly in accessing the end-to-side anastomosis and is possible only in presence of a long main bronchus.

The inverted version of this technique was reported by Eschapasse [57]: an end-to-end anastomosis between the trachea and the left main bronchus and an end-to-side anastomosis of the right main bronchus into the left main bronchus or into the low- 
er trachea, depending on the length of the right main bronchus. Grillo and colleagues [50] also described an end-toside anastomosis of the right main bronchus with the lower trachea, but this technique is rarely used because of its technical difficulty and high rate of complications at the anastomotic site due to excessive tension.

Right carinal pneumonectomy is the most frequent type of carinal resection for bronchogenic carcinoma. After transection at the level of the distal trachea and at the origin of the left main bronchus, the left main bronchus is intubated through the operative field. This is replaced by an oro-tracheal tube with the tip advanced in the left main bronchus before the anastomotic sutures are tied. After the anastomosis is completed, the tube is pulled back to check the air-tightness of the anastomosis.

When considering left carinal pneumonectomy, additional technical problems related to the presence of the aortic arch, should be considered. Complete circumferential mobilisation of the aortic arch is therefore needed for adequate exposure and mobilisation of the carina and the left main bronchus.

Occasionally, if cancer extends from the right upper lobe to the carina, carinal resection is associated with upper lobectomy with reimplantation of the intermediate bronchus. Reconstruction is generally performed by an end-to-end anastomosis of the left main bronchus with the trachea and an end-to-side anastomosis of the bronchus intermedius into the left main bronchus or into the lateral wall of the trachea if there is not excessive anastomotic tension.

Results: Results of carinal resections for bronchogenic carcinoma have shown a clear improvement over time. Although technical complexity of these procedures remains high and only few centres worldwide have obtained a wide range of experience, in the last decade the operative mortality has been reported under $10 \%$ with 5 -year survival rates ranging between $33 \%$ and $44 \%$ (table 4 ) [56, 58-64].

The largest published experience [56] from the group at Marie-Lannelongue Hospital in Paris includes a series of 119 patients undergoing carinal resection over a 24-year period. Histology was Non Small Cell Lung Carcinoma in 100 patients, adenoid cystic carcinoma in 8 , carcinoid in 5 , mucoepidermoid carcinoma in 4 and metastatic renal cell carcinoma in 2. Most patients (96) underwent right carinal pneumonectomy. Eleven patients underwent carinal resection without lung resection. The most frequent reconstruction technique consisted of end-to-end anstomosis of the left main bronchus with the trachea and an end-to-side anastomosis of the right main bronchus into the trachea. In two patients the right main bronchus and the carina were partially resected and the left main bronchus was anastomosed end-to-side to the defect. In 25 patients right carinal pneumonectomy was associated with Superior Vena Cava reconstruction. Resection was complete (R0) in 112 patients. Mediastinal nodal involvement (N2 - N3) was found in 27 patients. Operative mortality was $7 \%$. Long term survival in patients without mediastinal nodal involvement $(55 \%$ at 5 years; $31 \%$ at 10 years) was significantly higher if compared with patients with mediastinal lymphadenopathy (15\% at 5 years).

Similarly, Mitchell [62] in a recent large series has also reported a 51\% 5-year survival rate in patients N0 and a 12\% 5-year survival in patients with $\mathrm{N} 2$ or N3 disease, indicating the role of mediastinal nodes metastasis as the most significant adverse prognostic factor. Mediastinoscopy is therefore strongly recommended before resection. In the series by dePerrot [56] the actuarial 10-year survival was $100 \%$ for carcinoid tumours and $69 \%$ for adenoid cystic carcinoma.

\section{References}

1. Colice GL, Stukel TA, Dain B. Laryngeal complications of prolonged intubation. Chest 1989; 96: 877.

2. Pearson FG. A prospective study of tracheal injury complicating tracheostomy with a cuffed tube. Ann Otol Rhinol Laryngol 1968; 77: 867.

3. Pearson FG, Andrews MJ. Detection and management of tracheal stenosis following cuffed tube tracheostomy. Ann Thorac Surg 1971; 12: 359.

4. Wood DE. Bronchoscopic preparation for airway resection. Chest Surg Clin N Am 2001; 11: 735-748.

5. Wain JC. Postintubation tracheal stenosis. Chest Surg Clin N Am 2003; 13: 231-246.

6. Ciccone AM, DeGiacomo T, Venuta F, et al. Operative and non-operative of benign subglottic laryngotracheal stenosis. Eur J Cardiothorac Surg 2004; 26: 818-22.

7. Ogura JH, Powers WE. Functional restitution of traumatic stenosis of the larynx and pharynx. Laryngoscope 1964; 74: 1081-110.

8. Gerwat J, Bryce DP. The management of subglottic stenosis by resection and direct anastomosis. Laryngoscope 1974; 84: 940-947. 
9. Pearson FG, Cooper JD, Nelems JM, et al. Primary tracheal anastomosis after resection of the cricoid cartilage with preservation of recurrent laryngeal nerves. $J$ Thorac Cardiovasc Surg 1975; 70: 806.

10. D'Andrilli A, Ciccone AM, Venuta F, et al. Long term results of laryngo-tracheal resection for benign stenosis. Eur J Cardiothorac Surg 2008; 33: 440-3.

11. McCaffrey TV. Management of subglottic stenosis in the adult. Ann Otol Rhinol Laryngol 1991; 100: 90.

12. Maddaus MA, Toth JL, Gullane PJ, Pearson FG. Subglottic tracheal resection and synchronous laryngeal reconstruction. J Thorac Cardiovasc Surg 1992; 104: 1443.

13. Grillo HC, Mathisen DJ, Wain JC. Laryngotracheal resection and reconstruction for subglottic stenosis. Ann Thorac Surg 1992; 53: 54.

14. Couraud L, Jougon J, Velly JF. Surgical treatment of nontumoral stenosis of the upper airway. Ann Thorac Surg 1995; 60: 250-260.

15. Grillo HC, Donahue DM, Mathisen DJ, et al. Postintubation tracheal stenosis: treatment and results. J Thorac Cardiovasc Surg 1995; 109: 486-493.

16. Macchiarini P, Verhoye J, Chapelier A, et al. Partial cricoidectomy with primary thyrotracheal anastomosis for postintubation subglottic stenosis. J Thorac Cardiovasc Surg 2001; 121: 68.

17. Ashiku S, Kuzucu A, Grillo HC, Wright CD, Wain JC, Lo B, Mathisen DJ. Idiopathic laryngotracheal stenosis: Effective definitive treatment with laryngotracheal resection. J Thorac Cardiovasc Surg 2004; 127: 99-107.

18. Grillo HC, Mathisen DJ. Primary tracheal tumours: Treatment and results. Ann Thorac Surg 1990; 49: 69-77.

19. Choi NC. Radiation therapy in the management of tracheal cancer. In: Grillo HC, ed. Surgery of the trachea and bronchi. Hamilton, London: BC Decker, 2004: 791-802.

20. Abbott OA, Van Fleit WE, Roberto AE. Experiences with extending the indications for use of tracheal and bronchial grafts. J Thorac Surg 1955; 29: 217-237.

21. Beall Jr AC, Harrington OB, Greenberg SD, et al. Tracheal reconstruction with heavy Marlex mesh. Arch Surg 1963; 86: 960-968.

22. Carter MG, Streider JW. Resection of the trachea and bronchi: An experimental study. J Thorac Surg 1950; 20: 613-627.

23. Keshishian JM, Blades B, Beattie Jr EJ. Tracheal reconstruction. J Thorac Surg 1956; 32: 707-727.

24. Kramish D, Marfit HM. The use of a Teflon prosthesis to bridge complete sleeve defects in the human trachea. Am J Surg 1963; 106: 704-708.

25. Grillo HC, Dignam EF, Miura T. Extensive resection and reconstruction of mediastinal trachea without prosthesis or graft: an anatomical study in man. $J$ Thorac Cardiovasc Surg 1964; 48: 741-750.

26. Mulliken J, Grillo HC. The limits of tracheal resection with primary anastomosis: Further anatomical studies in man. J Thorac Cardiovasc Surg 1968; 55: 418-424.

27. Cooper JD. Tracheal resection - Comments and Controversies. In: Patterson GA, Cooper JD, Deslauriers D, et al. Eds: Pearson's Thoracic and esophageal surgery. Churchill Livingstone, New York 2008. Chap. 32.

28. Montgomery WW. Suprahyoid release for tracheal anastomosis. Arch Otolaryngol 1974; 99: 255-260.

29. Dedo HH, Fishman NH. Laryngeal release and sleeve resection for tracheal stenosis. Ann Otol Rhinol Laryngol 1969; 78: 285-96.

30. Mathisen DJ. Surgery of the trachea. Curr Prob Surg 1998; 35: 458-542.

31. Wright CD, Grillo HC, Wain JC, et al. Anastomotic complications after tracheal resection: prognostic factors and management. J Thorac Cardiovasc Surg 2004; 128: 731-9.
32. Yang KY, Chen YM, Huang MH, Perng RP. Revisit of primary malignant neoplasms of the trachea: clinical characteristics and survival analysis. Jpn J Clin Oncol 1997; 27: 305-9.

33. Licht PB, Friis S, Pettersson G. Tracheal cancer in Denmark: a nationwide study. Eur J Cardiothorac Surg 2001; 19: 339-45.

34. Bhattacharyya N. Contemporary staging and prognosis for primary tracheal malignancies: a population-based analysis. Otolaryngol Head Neck Surg 2004; 131: 639-42.

35. Gelder CM, Hetzel MR. Primary tracheal tumours: a national survey. Thorax 1993; 48: 688-92.

36. Gaissert HA, Grillo HC, Shadmehr MB, et al. Longterm survival after resection of primary adenoid cystic and squamous cell carcinoma of the trachea and carina. Ann Thorac Surg 2004; 78: 1889-96; discussion 1896-7.

37. Mathisen DJ. Tracheal tumours. Chest Surg Clin N Am 1996; 6: 875-98.

38. Regnard JF, Fourquier P, Levasseur P. Results and prognostic factors in resections of primary tracheal tumours: a multicenter retrospective study. J Thorac Cardiovasc Surg 1996; 111: 808-813.

39. Perelman MI, Koroleva N, Birjukov J, et al. Primary tracheal tumours. Semin Thorac Surg 1996; 8: 400-02.

40. Maziak DE, Todd TRJ, Keshavjee SH, et al. Adenoid cystic carcinoma of the airway: thirty-two-year experienc. J Thorac Cardiovasc Surg 1996; 112: 1522-32.

41. Gaissert HA, Grillo HC, Shadmehr BM, et al. Laryngotracheoplastic resection for primary tumours of the proximal airway. J Thorac Cardiovasc Surg 2005; 129: 1006-9.

42. Birchall M, Macchiarini P. Airway transplantation: a debate worth having? Transplantation 2008; 85: 1075-80.

43. Sato T, Tao H, Araki M, Ueda H, Omori K, Nakamura $\mathrm{T}$. Replacement of the left main bronchus with a tissueengineered prosthesis in a canine model. Ann Thorac Surg 2008; 86: 422-8.

44. Baiguera S, Birchall MA, Macchiarini P. Tissue-engineered tracheal transplantation. Transplantation 2010; 89: 485-91.

45. Macchiarini $\mathrm{P}$, Jungebluth $\mathrm{P}$, Go T, et al. Clinical transplantation of a tissue-engineered airway. Lancet 2008; 372 (9655): 2023-30.

46. Barclay RS, McSwan N, Welsh TM. Tracheal reconstruction without the use of grafts. Thorax 1957; 12: 177-180.

47. Abbott OA. Experience with the surgical resection of the human carina, tracheal wall and contralateral bronchial wall in cases of right total pneumonectomy. $J$ Thorac Surg 1950; 19: 906-922.

48. Hardin CA, Fitzpatrick MJ. Primary carcinoma of the carina and bifurcation successfully treated by resection and reconstruction. Surgery 1959; 46: 534-538.

49. Thompson DT, Doyle JA, Roncoroni AJ. Carinal resection, left pneumonectomy and right lung anastomosis for adenocystic basal cell carcinoma (cylindroma). Tho$\operatorname{rax} 1966 ; 24:$ 752-755.

50. Grillo HC, Bendixen HH, Gephart T. Resection of the carina and lower trachea. Ann Surg 1963; 158: 889-893.

51. Mathey J, Binet JP, Galey JJ, et al. Tracheal and tracheobronchial resections; technique and results in 20 cases. J Thorac Cardiovasc Surg 1966; 51: 1-13.

52. El-Baz N, Jensik R, Faber LP, Faro RS. One-lung highfrequency ventilation for tracheoplasty and bronchoplasty: A new technique. Ann Thorac Surg 1982; 34: 564-571.

53. McClish A, Deslauriers J, Beaulieu M, et al. High-flow catheter ventilation during major tracheobronchial reconstruction. J Thorac Cardiovasc Surg 1985; 89: 508-512.

54. Bjork VO, Carlens E, Craford C. The open closure of the bronchus and the resection of the carina and of the tracheal wall. J Thorac Surg 1952; 23: 419-428. 
55. Pearson FG, Todd TRJ, Cooper JD. Experience with primary neoplasms of the trachea and carina. $J$ Thorac Cardiovasc Surg 1984; 88: 511-518.

56. de Perrot M, Fadel E, Mercier O, et al. Long-term results after carinal resection for carcinoma: Does the benefit warrant the risk? J Thorac Cardiovasc Surg 2006; 131: 81-89.

57. Eschapasse H, Vahdat F, Gaillard J, Besso JC. Reflections on resection of the lower trachea and bronchial bifurcation. Ann Chir Thorac Cardiovasc 1967; 6: 63-70.

58. Deslauriers J, Beaulieu M, McClish A. Tracheal sleeve pneumonectomy. In: Shields TW, editor. General thoracic surgery. Edition 3. Philadelphia: Lea and Febiger; 1989. p. 382-7.

59. Tsuchiya R, Goya T, Naruke T, Suemasu K. Resection of tracheal carina for lung cancer. Procedure, complications, and mortality. J Thorac Cardiovasc Surg 1990; 99: 779-87.

60. Vogt-Moykopf I, Meyer G, Naunheim K, et al. Bro- choplastic techniques for lung resection. In: Baue AE, Geha AS, Hammond GL, Laks H, Naunheim KS, editor. Glenn's thoracic and cardiovascular surgery. Edition 5. Norwalk, CT: Appelton and Lange; 1991. p. 403-17.

61. Mathisen DJ, Grillo HC. Carinal resection for bronchogenic carcinoma. J Thorac Cardiovasc Surg 1991; 102: 16-22.

62. Mitchell JD, Mathisen DJ, Wright CD, et al. Resection for bronchogenic carcinoma involving the carina: Long-term results and effects of nodal status on outcome. J Thorac Cardiovasc Surg 2001; 121: 465-471.

63. Roviaro G, Vergani C, Maciocco M, et al. Tracheal sleeve pneumonectomy: Long-term outcome. Lung Cancer 2006; 52: $105-110$

64. Regnard JF, Perrotin C, Giovannetti R, et al. Resection for tumours with carinal involvement: technical aspects, results, and prognostic factors. Ann Thorac Surg 2005; 80: 1841-6.

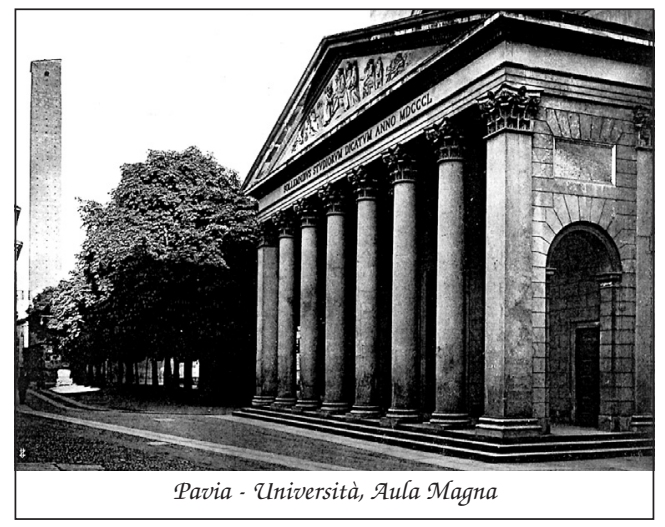

